TI 2012-112/ VIII

Tinbergen Institute Discussion Paper
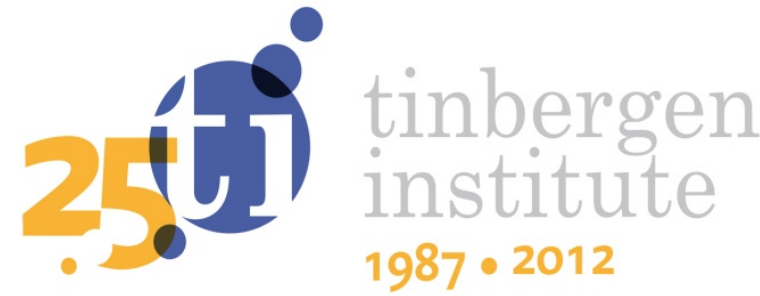

\title{
Climate Change Skepticism in the Face of Catastrophe
}

\author{
Mark Kagan
}

Faculty of Economics and Business Administration, VU University Amsterdam, and Tinbergen Institute. 
Tinbergen Institute is the graduate school and research institute in economics of Erasmus University Rotterdam, the University of Amsterdam and VU University Amsterdam.

More TI discussion papers can be downloaded at http://www.tinbergen.nl

Tinbergen Institute has two locations:

Tinbergen Institute Amsterdam

Gustav Mahlerplein 117

1082 MS Amsterdam

The Netherlands

Tel.: +31(0)205251600

Tinbergen Institute Rotterdam

Burg. Oudlaan 50

3062 PA Rotterdam

The Netherlands

Tel.: +31(0)10 4088900

Fax: $+31(0) 104089031$

Duisenberg school of finance is a collaboration of the Dutch financial sector and universities, with the ambition to support innovative research and offer top quality academic education in core areas of finance.

DSF research papers can be downloaded at: http://www.dsf.nl/

Duisenberg school of finance

Gustav Mahlerplein 117

1082 MS Amsterdam

The Netherlands

Tel.: +31(0)20 5258579 


\title{
Climate Change Skepticism in the Face of Catastrophe
}

\author{
Mark Kagan * $* \S$
}

September 29, 2014

\begin{abstract}
Despite overwhelming scientific evidence for man-made climate change, many people remain skeptical. While this phenomenon of 'climate-skepticism' prevents implementation of environmental policies around the globe, it is ignored in economic models of climate change. In this paper we fill this gap by modeling policymakers with varying levels of skepticism facing a climate change catastrophe. We calculate optimal emission and consumption paths for various levels of belief in man-made climate change to explore the true cost of climate skepticism. Our findings are as follows. First of all we find that when facing catastrophic climate change even a completely skeptic policy (believing there is zero probability that climate change is connected to $\mathrm{CO} 2$ emissions) will not lead to unbounded climate change and emissions. Second, we find there is still a significant loss due to climate-change resulting from skepticism if emission-driven climate change is real. Lastly, we find that moderate levels of skepticism will still lead to significant cuts in greenhouse gas emissions.
\end{abstract}

JEL Classification: Q54, Q58

Keywords: climate change, catastrophic damages, climate skepticism, uncertainty

${ }^{*}$ Corresponding Author at: Department of Spatial Economics, VU University Amsterdam De Boelelaan 1105, 1081 HV, Amsterdam, The Netherlands, e-mail: m.s.kagan@vu.nl, Fax: +31-20-5986004, Tel: $+31-62-1809957$

†Tinbergen Institute, The Netherlands

${ }^{\ddagger}$ Department of Economics, VU University Amsterdam and The Tinbergen Institute, The Netherlands

$\S$ The author is grateful to the ERC Advanced Grant Political Economy of Green Paradoxes' for financial support, to Rick van der Ploeg and Yacov Tsur for help in clarifying the initial idea, to Cees Withagen and Gerard van der Meijden for all their help, and to the participants of the 2013 CREE workshop, the 2014 SURED conference and the 2014 World Congress on Environmental and Resource Economics for useful feedback. 


\section{Introduction}

Anthropogenic climate change is an example of an externality, where actions of individual agents result in loss of utility for the entire society. However, the problem of climate change is special because, despite overwhelming scientific evidence that supports it, a significant portion of the population does not believe climate change is man-made. In this paper we define this phenomenon as climate-skepticism.

There are of course other types of climate-skeptic views, for example a belief that temperatures are not going up at all, or a belief that climate change will not result in severe damages. However, in this paper we focus on the skepticism about the manmade nature of climate change. Firstly, this type of climate-skepticism is fairly prevalent specifically in one of the largest $\mathrm{CO}_{2}$ emitting nations- the United States. According to Leiserowitz et al. (2013), while a majority of the US population (62\%) believes the temperatures are increasing, only a minority (49\%) believes that climate change is manmade. Secondly, skepticism about the man-made nature of climate change is common in the rhetoric of policy makers. A prime example of climate skepticism is a statement by Mitt Romney, the former republican nominee for the U.S. presidency, who said in 2012: "My view is that we do not know what is causing climate change on this planet. And the idea of spending trillions and trillions of dollars to try to reduce CO2 emissions is not the right course for us." Climate skepticism has been a steady presence in our society, hampering implementation of stringent environmental policy. Lastly, as I will discuss when presenting the literature, skepticism in regard the warming itself or the severity of the damages have largely been already covered in the literature by "business as usual" scenarios.

It is thus important to understand the consequences of skepticism about the manmade nature of climate change. Given the overwhelming scientific evidence, climate change is most likely driven by human activity. Does that mean that climate skeptic policies lead to uncontrolled climate change? Can we assign a monetary cost to climate skepticism? If the cost is very large, then maybe more resources should be invested into convincing the population that climate change is emission-driven. Since most of the world's governments are democratically elected, a less skeptic population would result in a less skeptic policymaker. On the other hand, we must consider a possibility, however unlikely, that the skeptics are right. What is the true cost of a stringent environmental policy (from a skeptic's point of view)?

The purpose of this paper is to explore these problems in a formal theoretical and calibrated framework. The main contribution of this paper is formally accounting for the skepticism of a policy-maker in a fully calibrated general equilibrium model with catastrophic climate change damages. Within our model we quantify the level of climate skepticism as the probability the policy-maker assigns to climate change being random 
rather than emission-driven.

Our paper contributes to a larger field of literature modeling structural uncertainty about climate change. The works in this field consider optimal policies in face of uncertainty about true values of climate change parameters. A simple way to study structural uncertainty is the 'sensitivity analysis' approach, using a deterministic model like DICE (Nordhaus, 1992) and sampling the input parameters from prior distributions (formed based on expert opinions). For each sample the model is simulated resulting in a distribution of carbon cost that reflects uncertainty about climate change (see Nordhaus and Popp (1997) and Stern (2007)). They find that the expected values of these carbon cost distributions are much higher than in the certainty case, resulting in more stringent policy recommendations. Most of these early studies do not explicitly include uncertainty in their optimization, but rather study uncertainty by analyzing their model for a range of parameter values. One exception is (Pizer, 1999) which solves the model with uncertainty included explicitly, finding that optimal policies that maximize expected utility are much more stringent than those optimal for the certainty equivalent case.

This approach is fairly limited as it requires us to assume a distribution for each climate change parameter. There are still deep uncertainties about climate change that cannot be modeled using this approach. As a result, more recent studies adopt more sophisticated approaches. Weitzman (2009) uses fat-tailed distributions of climate parameters to demonstrate that under 'deep uncertainty' about climate change, cost-benefit analysis of emissions policies is impossible. Pindyck (2012) models uncertainty about future temperature with flexible distributions of climate damages finding that uncertainty about temperature influences Willingness to Pay (WTP) for climate change more than higher expected values. Hennlock (2009) uses prior distributions similar to earlier studies, but introduces ambiguity aversion (finding the optimal policy for reducing the damage in the worst-case scenario rather than maximizing expected utility). Crost and Traeger (2011) focus on uncertainty in climate damages, introducing uncertainty in every period rather than ex-ante, and breaking down the effect of uncertainty into risk aversion and inter-temporal sustainability. Just like the studies using the simpler approach to uncertainty, all of the studies mentioned above, concur that more uncertainty leads to more stringent optimal environmental policy. One exception to that is Athanassoglou and Xepapadeas (2012) who find that optimal emissions can increase with uncertainty, but only if damage control (adaptation) technology is very advanced.

A common feature of climate models dealing with uncertainty, that is somewhat related to modeling climate skepticism, is learning. Models that allow for learning, focus on the question whether it is best to reduce emissions now or wait until more is known about climate change. The option of 'waiting until we know more' is similar to the arguments of skeptics like Mitt Romney mentioned earlier. Most of these studies focus on learning about 'climate sensitivity' - how far temperature rises due to an increase in greenhouse gas 
emissions. Kelly and Kolstad (1999) consider a model where the true value of climate sensitivity is unknown, but can be pinned down over time through Bayesian learning. Their model is fairly complex, and they solve it using numerical methods very similar to the ones used in our paper. They find that it will take many years to resolve the uncertainty about climate sensitivity, leading to many years of suboptimal decisions. Leach (2007) extends these results by allowing for uncertainty and learning about both climate sensitivity and the persistence of greenhouse gas accumulation, finding that learning takes too long and leads to long-term inefficient policies. Van Wijnbergen and Willems (2012) is the paper that is closest to our work, which actually explicitly models climate-skepticism in the context of learning about climate change. The study concludes that climate skeptics have an incentive to reduce emissions, as emission reduction will facilitate learning about the nature of climate change. The study justifies its conclusion by the irreversability of global warming. Learning through emitting less is better than learning through emitting more, because emitting more is irreversible. Our study differs from Van Wijnbergen and Willems (2012) as we are more interested on the optimal level of emission for various levels of skepticism and how it is affected by catastrophic climate change. Thus we use a more sophisticated, calibrated general equilibrium model, and in order to not complicate the problem too much we keep the level of skepticism constant.

Most of the literature on climate change uncertainty focuses on the possibility of more severe (rapid or disastrous) climate change than is generally expected. It is thus usually concluded that uncertainty leads to a more drastic optimal environmental policy. Our study seeks to add to this literature by going against this trend, focusing on a potentially weaker connection between climate change and emissions. Uncertainty in our study manifests itself as skepticism - perception of climate change as a potentially random and uncontrollable phenomenon. Many environmental papers do implicitly consider a fully skeptic policy maker. The frequently used DICE model (Nordhaus, 2008), uses a Business as Usual scenario to represent the consequences of not doing anything about climate change (the completely climate skeptic case). It is usually assumed that in such a case, emissions will grow at the same rate as they have over the past years. Our study takes a more complex approach to the problem of skepticism. First of all, our analysis goes beyond the completely skeptic policy maker. We explore what the optimal policy is for a partially skeptic policy maker, who believes that climate change may be exogenous but only with a certain probability. Secondly, our model contains a more complex damage specification which makes even the problem of a completely skeptic policy maker less straightforward.

This paper considers the case of catastrophic damage induced by abrupt climate change. The onset of the abrupt catastrophic event is uncertain, but its probability distribution is known. The catastrophe probability function is increasing in temperature. This damage specification is used because it makes the fully skeptic policymaker's prob- 
lem non-trivial. An abrupt climate catastrophe results in non-linear dynamics affecting the policymaker's consumption and savings decisions even if he does not believe he can control climate change through emissions. Furthermore, as stated by Weitzman (2009)'s 'dismal theorem' any cost-benefit analysis of climate change is incomplete without considering the upper-bound of damages (the worst possible scenario). Hence the climate catastrophic event we use drives mankind to some very low subsistence-level of consumption. Two examples of such catastrophes are an abrupt rise in sea level or an explosive outburst of diseases resulting from a climate shift. One key assumption about the damage specification that drives our results is that post-catastrophic consumption levels are independent of the capital prior to catastrophe. The damage specification we use is similar to the one used by Tsur and Zemel (2008), Tsur and Zemel (2009), Karp and Tsur (2011) and Tsur and Withagen $(2012)^{1}$. In particular Tsur and Zemel (2008) examines how a market economy (without social-welfare optimization) reacts to catastrophic climate change. The study finds that potential catastrophe actually increases emissions because of increased discounting of the future due to the possibility of a catastrophe. Given that there are no externalities other than climate change, this result is the same as that of an optimal policy of a completely skeptic policy maker. However, Tsur and Zemel only look at the long-run equilibrium of the model. Since by our definition, a skeptic policy maker assigns a certain probability to a possibility of random climate change, our model includes stochastics, and hence we need to consider behavior outside the steady state. As a result, we provide a solution to the dynamic model with catastrophic climate change, leading to different conclusions. The catastrophic climate damages we use is also similar to tipping point/threshold models (Keller et al. (2004), Lemoine and Traeger (2012)), where the nature of climate damages changes after temperature exceeds some (unknown) threshold value. While we do not explicitly model threshold effects some of the dynamics we get are fairly similar to those found in these studies.

Our results are threefold. First, we find that when potential damages are catastrophic, even a completely climate-skeptic policy does not result in unbounded climate change. A potential catastrophe causes the policy-maker to fear he will soon switch to a subsistencelevel. With no adaptation, capital is useless after the catastrophe occurs so capital is depleted, leading to a scale-back of the economy. This in turn leads to fewer emissions resulting in a slowdown in temperature increase. Second, we find that the additional long-run expected increase in temperature resulting from a fully skeptic policy is over 6 degrees Celsius (compared to an increase of 1.5 degree under the optimal climate-aware policy). Third, we find that moderate skepticism (a belief that climate change may be man-made but isn't necessarily) leads to emission cuts that are still fairly stringent. The catastrophic consequences of climate change provide sufficient incentives to cut emissions

\footnotetext{
${ }^{1}$ Tsur and Withagen (2012) actually use a slightly different specification, allowing for adaptation capital which decreases catastrophic damages
} 
even to someone who attaches a small probability to man made climate change. Thus even a policy-maker who believes there is a 10 percent chance that climate change is manmade will prefer to cut emissions by over 50 percent leading to a temperature increase of just 3 degrees Celsius.

The rest of our paper is outlined as follows. Section 2 describes the components of the integrated assessment model. Section 3 characterizes the three optimal policy problems (completely skeptic, climate-aware, and moderately skeptic) and describes the solution method used to solve them. Section 4 presents the optimal policies, simulations of the economy, and welfare analysis for all cases. Section 5 concludes.

\section{Model}

We are interested in the global environmental and economic outcomes from climateskeptic and climate-aware policy maker/social optimizers. While in reality the policy is set through global agreements on emission standards and implemented by each individual national government for simplicity (as done in many other Integrated Assessment Models), we use a representative agent model. We assume that a global policy maker can set global consumption and $\mathrm{CO}_{2}$ emissions directly. To make modeling uncertainty easier we use a discrete-time infinite-horizon model.

In the economy, output is produced with capital $K$ and fossil fuel energy $X$. The production function $F(K, X)$ has decreasing returns to scale. Capital depreciates at rate $\delta$ while fossil fuel has extraction cost $p$ per unit of energy. ${ }^{2}$ Consumers own firms and consume $C$ resulting in the intertemporal resource constraint:

$$
K_{t+1}=(1-\delta) K_{t}+F\left(K_{t}, X_{t}\right)-p X_{t}-C_{t}
$$

Emissions from fossil-fuel consumption increase $\mathrm{CO}_{2}$ concentration concentration according to the following law of motion:

$$
S_{t+1}=e X_{t}+(1-\gamma)\left(S_{t}-S_{b}\right)+S_{b}
$$

where $S$ is $\mathrm{CO}_{2}$ concentration, $e$ is amount of $\mathrm{CO}_{2}$ emissions per unit of fossil fuel energy and $S_{b}$ is the pre-industrial level of $\mathrm{CO}_{2}$ concentration. $\mathrm{CO}_{2}$ concentration depreciates through absorption at rate $\gamma$, and . This is of course just an approximation to the threereservoir carbon stock system used by Nordhaus. We discuss this simplification further when we calibrate the model with numerical parameter values.

The two expressions above are fairly common to integrated assessment models. The

\footnotetext{
${ }^{2}$ We assume the fossil-fuel reserves are inexhaustible. It is a necessary assumption that makes our problem tractable, and given the vast new reserves of oil and gas that have been discovered due to the fracking technology, the assumption isn't entirely unrealistic
} 
modeling of climate change expectations is where our model differs. Expectations of future temperature are conditional on the skepticism of the policy maker. A completely climate-aware policy maker (no skepticism) believes that $\mathrm{CO}_{2}$ concentration affects the global temperature through radiative forcing. This process is represented by the following law of motion:

$$
T_{t+1}=\alpha T_{t}+\beta \ln \left(\frac{S_{t}}{S_{b}}\right)+\epsilon_{t}, \epsilon_{t} \sim N\left(0, \sigma_{\epsilon}\right)
$$

where $T$ is global temperature, $\epsilon$ is the stochastic component. The climate sensitivity (equal in this case to $\beta /(1-\alpha)$ ) measures the magnitude of the radiative forcing mechanism on temperature. The true value of climate sensitivity is hard to quantify due to the complexity of the carbon cycle, but our study assumes it is known and certain. In addition to the climate-aware policy maker, we also introduce a climate-skeptic policy maker, who believes with a certain probability that temperature is random, represented by the following simple auto-regressive process:

$$
T_{t+1}=\phi T_{t}+\zeta_{t}, \zeta_{t} \sim N\left(0, \sigma_{\zeta}\right)
$$

There are many ways to model skeptic expectations of temperature. We use a simple $\mathrm{AR}(1)$ process mostly to make the computation easy. In order to reconcile such skeptic expectations with a rise of .75 degrees that the planet has experienced we pick $\phi$ so that it is very close to 1 . This makes the temperature process behave closer to a random walk, rather than a mean-reverting process. This makes a large rise in temperature probable under the skeptic scenario. We model the level of skepticism a policymaker has by the parameter $\pi^{S K}$ - the probability that the random climate change scenario is the true one according to the policy maker's beliefs. Thus the general expression for the policy-maker's expectation of climate change is:

$$
E\left(T_{t+1}\right)=\pi^{S K}\left(\phi T_{t}+\zeta_{t}\right)+\left(1-\pi^{S K}\right)\left(\alpha T_{t}+\beta \ln \left(\frac{S_{t}}{S_{b}}\right)+\epsilon_{t}\right)
$$

We model climate change damages as a catastrophic event that occurs as a result of a shift in temperature. A real analogue of this catastrophe could be a change in the gulfstream current or a rapid rise of the sea level. Another way a catastrophe could manifest itself could be runaway climate change due to increased positive feedback in the climate system. For example, higher temperature could lead to the melting of the permafrost in the Siberian thundra. As a result of the meltdown vast quantities of green house gases contained in the ice are released, resulting in ever-increasing temperatures. After the catastrophe occurs the world switches to a subsistence economy - where each period a small value $\bar{C}$ is consumed. Then the value of social welfare after the catastrophe occurs 
is:

$$
\psi=\frac{U(\bar{C})}{1-\rho}
$$

where $U(C)$ is the consumer's utility function and $\rho$ is the discount factor. A key assumption made in our model is that capital accumulated prior to the catastrophe is irrelevant in the post-catastrophic world. The justification for this process is that the catastrophe drastically reduces the productivity of capital, and through natural destruction reduces the capital stock to the same low value no matter how high it was before the catastrophe. This would lead directly to a subsistence steady state immediately after the catastrophe. A more realistic way would be to model the climate catastrophe as a drastic reduction in the total productivity factor or the marginal productivity of capital (due to a decrease in the world's population). However that would make the problem much more complex (endogenizing the continuation value), making it less tractable. The extent to which this simplifying assumption drives our results will be discussed further, when we describe our results in Section 4.

We now derive the expression for social welfare. However, because our model uses discrete time, we must first specify the sequence of events in every period. For every period $t$, the representative agent first sets $C_{t}$, and $X_{t}$ given $K_{t}, S_{t}$ and $T_{t}$. After this decision catastrophe may occur. If it does occur - then the representative consumer switches to subsistence consumption. Otherwise $K_{t+1}, S_{t+1}$, and $T_{t+1}$ are set given $C_{t}$ and $X_{t}$. Thus, assuming the catastrophe occurs at time $t_{1}$, then the expression for social welfare is:

$$
\sum_{t=0}^{t_{1}} \rho^{t} U\left(C_{t}\right)+\rho^{t_{1}} \psi
$$

However the timing of the catastrophe is uncertain and endogenous, increasing with temperature. What is known to the policymaker is $\lambda(T)$ - the survival probability. This is the probability that no catastrophe occurs for every possible value of $T$. (This is often used to model catastrophic climate change (see Tsur and Zemel (2008) and others).

Thus the resulting expression for expected social welfare is:

$$
\sum_{t=0}^{\infty} \rho^{t}\left(U\left(C_{t}\right)+\psi\left(1-\lambda\left(T_{t}\right)\right)\right) Y(t)
$$

where

$$
Y(t)=\left\{\begin{array}{cc}
1 & t=0 \\
\prod_{j=0}^{t-1} \lambda\left(T_{j}\right) & t>0
\end{array}\right.
$$

The intuition behind the expression above is the following. At each period $t$ social welfare is equal to utility of consumption plus the subsistence consumption level for all future periods if catastrophe occurs. This welfare is then multiplied by the discount factor $Y(t)$ which includes the probability that catastrophe does not occur before $t$. 


\section{Solving for Optimal Policy}

In this section we outline the path to solving the optimal policy problem. We first solve the problem of optimal consumption and fossil fuel use for the extreme cases: the completely climate-skeptic policy maker $\left(\pi^{S K}=0\right)$ and a completely climate-aware one $\left(\pi^{S K}=1\right)$. The problem of a moderately skeptic policy maker $\left(0<\pi^{S K}<1\right)$ is similar to that of a climate-aware one thus we don't describe that solution method separately.

\subsection{Skeptic Policymaker}

We solve the problem of the fully skeptic policymaker by assuming that climate change is random. Recall however, that while such a policymaker perceives temperature to be exogenous he is still aware of the potential of a climate catastrophe that occurs with a probability $\lambda(T)$. To solve the fully skeptic policy-maker's problem we must maximize social welfare in (2.8) subject to constraints (2.1), and (2.4). (constraint (2.2) is irrelevant to the fully skeptic policy maker as a change $\mathrm{CO}_{2}$ concentration does not lead to any consequences as far as he is concerned). Since $T_{t}$ is an exogenous stochastic process, the problem becomes a typical Ramsey problem with a twist randomly varying discount factor. This problem leads us to the following conditions that the optimal solution must follow.

$$
\begin{array}{r}
U^{\prime}\left(C_{t}\right)=E\left(U^{\prime}\left(C_{t+1}\right) \rho \lambda\left(T_{t}\right)\left((1-\delta)+F_{K}\left(K_{t+1}, X_{t+1}\right)\right)\right) \\
F_{X}\left(K_{t}, X_{t}\right)=p
\end{array}
$$

The first condition is similar to the standard Euler equation, requiring the current marginal utility of consumption to be the same as the discounted marginal utility of investment. The key difference from the standard Euler question, is that in addition to the discounting factor $\rho$, the future utility of consumption is multiplied by the survival probability $\lambda\left(T_{t}\right)$. The second condition requires the marginal productivity of fossil-fuels to be equal to the fossil-fuel price.

In order to solve for the optimal skeptic policy we need to specify functional forms for utility, production and survival probability functions. They are as follows:

$$
\begin{array}{rlcll}
U(C) & = & \frac{C^{1-\eta}}{1-\eta} & & \eta>0 \\
F(K, X) & = & A K^{\kappa} X^{\omega} & & \kappa+\omega<1 \\
\lambda(T) & = & 1-\left(1+\exp \left(\frac{\tau-T}{v}\right)\right)^{-1} & & v>0
\end{array}
$$

where $\eta, \kappa, \omega, \tau$, and $v$ are all parameters. The CRRA utility function and Cobb-Douglas production function are fairly standard for macroeconomic models. There is no precedent however for survival probability function $\lambda$. Though Tsur and Zemel (2008) model the 
climate change catastrophe in a similar fashion, that study is focused on the long-run equilibrium and thus does not need to specify a functional form for $\lambda$. We chose the functional form in (3.5) because it is between 0 and 1 for all values of $T$ and is monotonically decreasing in $T$. This is logical as survival probability should decrease with climate change (as probability of a climate catastrophe increases.)

Substituting the utility and production functions defined in (3.3) and (3.4) into the equations above, we arrive at the Euler equation for the skeptic policy-maker:

$$
C_{t}^{-\eta}=E\left(C_{t+1}^{-\eta} \rho \lambda\left(T_{t}\right)\left((1-\delta)+\kappa A K_{t+1}^{\kappa-1}\left(\frac{p K_{t+1}^{-\kappa}}{A \omega}\right)^{\frac{\omega}{\omega-1}}\right)\right)
$$

We cannot obtain a closed-form solution for $C$ that satisfies (3.6), so we solve the problem numerically using projection analysis. The parameter values used for the numerical solution are presented in Table 1. For more details on the projection method and the way we implemented it, see the description in Appendix A.

\subsection{Climate Aware Policymaker}

The next step is to solve for the optimal behavior of a non-skeptic policy maker. To do so we must maximize (2.8) under constraints (2.1) - (2.3). The Lagrangian for this problem is as follows:

$$
\begin{aligned}
L & =E\left[U\left(C_{t}\right)+\left(1-\lambda\left(T_{t}\right)\right) \psi+\rho \lambda\left(T_{t}\right)\left(U\left(C_{t+1}\right)+\left(1-\lambda\left(T_{t+1}\right)\right) \psi+\rho \lambda\left(T_{t+1}\right) V_{t+2}\right)\right. \\
& +\mu_{t}^{K}\left(K_{t+1}-(1-\delta) K_{t}-A K_{t}^{\kappa} X_{t}^{\omega}+p X_{t}+C_{t}\right) \\
& +\mu_{t}^{S}\left(S_{t+1}-e X_{t}-(1-\gamma)\left(S_{t}-S_{b}\right)-S_{b}\right) \\
& \left.+\mu_{t}^{T}\left(T_{t+1}-\alpha T_{t}-\beta \ln \left(S_{t} / S_{b}\right)-\epsilon_{t}\right)\right]
\end{aligned}
$$

where

$$
V_{t+2}=E\left(U\left(C_{t+2}\right)+\left(1-\lambda\left(T_{t+2}\right)\right) \psi+\sum_{j=t+3}^{\infty}\left(U\left(C_{j}\right)+\left(1-\lambda\left(T_{j}\right)\right) \psi\right) \prod_{i=t+2}^{j-1} \rho \lambda\left(T_{i}\right)\right)
$$

$V_{t+2}$ represents the 2-period ahead value function. It is endogenous to the decision of the representative agent because the next-period temperature $T_{t+1}$ affects the survival probability $\lambda\left(T_{t+1}\right)$, which increases the total discount factor of consumption $C_{t+2}$. The first order conditions (presented below) obtained from the Lagrangian are more complex 
than the ones we obtain in the skeptic case:

$$
\begin{aligned}
\frac{d L}{d K_{t+1}}=\mu_{t}^{K}+\rho \lambda\left(T_{t}\right) \mu_{t+1}^{K}\left(-(1-\delta)-\kappa A K_{t}^{\kappa-1} X_{t}^{\omega}\right) & =0 \\
\frac{d L}{d S_{t+1}}=\mu_{t}^{S}+\rho \lambda\left(T_{t}\right)\left(-(1-\gamma) \mu_{t+1}^{S}-\mu_{t+1}^{T} \frac{\beta}{S_{t}}\right) & =0 \\
\frac{d L}{d T_{t+1}}=\mu_{t}^{T}+\rho \lambda\left(T_{t}\right)\left(-\lambda^{\prime}\left(T_{t+1}\right) \psi+\rho \lambda^{\prime}\left(T_{t+1}\right) V_{t+2}-\alpha \mu_{t+1}^{T}\right) & =0 \\
\frac{d L}{d C_{t}}=C_{t}^{-\eta}+\mu_{t}^{K} & =0, \\
\frac{d L}{d X_{1 t}}=\mu_{t}^{K}\left(-\omega A K_{t}^{\kappa} X_{1 t}^{\omega-1}+p\right)-\mu_{t}^{S} e & =0
\end{aligned}
$$

where $\mu_{t}^{K}, \mu_{t}^{S}$, and $\mu_{t}^{T}$ are shadow prices of capital, atmospheric $C O_{2}$ stock and temperature respectively. Expressions (3.8) and (3.11) are the same as in the skeptic case. However, unlike the skeptic, the climate-aware policymaker is aware of the link between emissions and catastrophic climate change. Hence (3.12) is more complex, making the shadow price of the $\mathrm{CO}_{2}$ stock endogenous in the expression that determines $X$. Expressions (3.9) and (3.10) specify the evolution of the shadow prices of temperature and $\mathrm{CO}_{2}$ stock. These two expressions demonstrate the complexity level of the climate-aware policy-maker's problem. The catastrophe probability $\lambda$ is endogenous to the policymaker's decision, resulting in an endogenous-discounting mechanism described in Tsur and Zemel (2008). With the discount-rate endogenous, the two-period ahead value function $V_{t+2}$ becomes endogenous in the first order condition (3.10). Because of this we cannot simplify the first order conditions much further. Therefore we use the value function iteration method to solve this problem. We follow the algorithm outlined in Kelly and Kolstad (2001), specifically well-suited for solving integrated assessment models with an infinite horizon. The Bellman equation for the problem is:

$$
V\left(K_{t}, S_{t}, T_{t}\right)=\max _{C_{t}, X_{t}} U\left(C_{t}\right)+\left(1-\lambda\left(T_{t}\right)\right) \psi+\rho \lambda\left(T_{t}\right) E\left(V\left(K_{t+1}, S_{t+1}, T_{t+1}\right)\right)
$$

Note that once we know the true expression for $V$, finding the optimal control variables is fairly straightforward - just solving a constrained optimization problem. We use a neural-network approximation to $V$ and a Newton-Rhapson algorithm to find the best approximation. Then once we know the value of $V$ we use a Sequential Quadratic Programming algorithm to find the optimal $C$ and $X$ at every point in time and simulate the economy. For a more detailed description of the algorithm see Appendix A.2.

\subsection{Calibration}

Similar to many environmental economic studies, we calibrate the model so that one period is equal to 10 years. For many parameters we use the same calibration as in 
Table 1: This table contains a list of pkarameter values used in the numerical solutions and simulations.

\begin{tabular}{rrrr}
\hline Parameter & Value & Parameter & Value \\
\hline$\alpha$ & 0.658 & $A$ & 2.87 \\
$\beta$ & 1.47 & $\phi$ & 0.99 \\
$\delta$ & 0.5 & $\sigma_{\zeta}$ & 0.185 \\
$\gamma$ & 0.962 & $\sigma_{\epsilon}$ & 0.185 \\
$\eta$ & 2 & $\psi$ & 0.2 \\
$\kappa$ & 0.35 & $S_{b}$ & 281 \\
$\omega$ & 0.05 & $v$ & 1.45 \\
$p$ & 0.16 & $\tau$ & 10 \\
$\rho$ & .9 & $\mathrm{e}$ & 36.6 \\
\hline
\end{tabular}

Rezai et al. (2012) due to similarity between the models (differing only in price of oil and damage specification). The discount factor $\rho$ is set to 0.9 corresponding to roughly $0.96 \%$ annual rate of pure time preference. The elasticity of intertemporal substitution $\eta$ is 2 .

\subsubsection{Production Parameters}

The production elasticity of capital $\kappa$ is set to .35 . We set the rate of decay of capital to .5 which corresponds to about $6.7 \%$ annually. We then use current global economic data (source: the World Bank(2012)) to calibrate the rest of the parameters. Current capital stock is $K_{0}=2$ (US $\$ 100$ Trillion), and energy consumption over the past decade is $X_{0}=1.1$ (100 Trillion $\mathrm{kg}$ of oil equivalent). Global GDP over the past decade is $F_{0}=3.65$ (US $\$ 100$ Trillion). Assume up until now the world has been functioning under skeptic assumptions. Then the cost of energy should be equal to its marginal productivity, so $p X_{0}=\omega F_{0}$. Given that according to the EIA the energy expenditure to GDP ratio is around $5 \%$ we set $\omega=\frac{F_{0}}{p X_{0}}=.05$. Then we solve for $A$ by $A=F_{0} /\left(K_{0}^{\kappa} X_{0}^{\omega}\right)=2.87$. We can now solve for $p=\frac{\omega F_{0}}{X_{0}}=.16$.

\subsubsection{Climate Parameters}

The initial CO2 concentration $S_{0}$ is set to 388 parts par million volume $\mathrm{CO}_{2}$ (ppmv) (NOAA, 2010), while the pre-industrial level $S_{b}$ is set to 281 ppmv. We take a barrel of oil to be equivalent to $1 / 10$ ton carbon and 2.13 gigaton carbon ( $\mathrm{GtC}$ ) to be equivalent to 1 ppmv. This results in $e=36.6$ (ppmv per $100 \mathrm{~kg}$ of oil equivalent). This yields around 40 ppmv emissions for the last decade and approximately 4 ppmv or 8.32 GtC per year, which corresponds to the real amount of $\mathrm{CO}_{2}$ emissions in 2010, (BP Statistical Review of World Energy, 2011). However the actual increase of CO2 concentration in 2010 was around $2.42 \mathrm{ppmv}$ (NOAA, 2010) leading to a depreciation factor of $(4 / 2.42) / 388=.0038$ per year, and $3.8 \%$ per decade leading to $\gamma=.962$. For the parametrization of the carbon 
cycle we follow Kelly and Kolstad (1999) setting $\alpha=.658$ and $\beta=1.47$. We assume a rather grim catastrophic scenario for climate change (following Weitzman (2009) dismal theorem that the lower bound of climate damages influences the cost-benefit analysis the most). We assume that global consumption is reduced by $90 \%$ leading to consumption of $\$ 20$ Trillion per decade (i.e. $\bar{C}=.2$ ). There is no precedent in literature for calibrating the survival probability $\lambda$. Given how extreme the catastrophe is, we set the probability of it happening very low. This is once again in line with Weitzman's dismal theorem, which insists that a low-probability high-impact scenario will dominate the cost-benefit analysis. We calibrate $\lambda$ so that the initial probability of a climate catastrophe is as low as $.1 \%$ and that it will reach 50 percent when temperature rises to 10 degrees Celsius (setting $\tau=10$ and $v=1.45$ ).

\subsection{Steady State}

Before we present the optimal policy solutions and dynamic simulations of the economy we discuss the steady state solutions. Using the first order conditions (3.1) - (3.2) and (3.8) - (3.12) we can derive the steady state values for the skeptic and climate aware policy makers respectively. The steady state for the skeptic case has a closed-form expression and is fairly straightforward. Finding the steady state for the climate-aware policy maker is harder, as there are no analytical first-order conditions. Then using a Newton-Rhapson method we find steady state values that minimize the differences between the left-side and the right-side of these conditions which must hold in the steady state(derived from (3.8) - (3.12)). The resulting steady-state values for state and control variables (for both types of policy-makers) are presented in table 2. Note that the steady state for the climateaware policy maker is many decades into the future, as it will take a while for the climate system to get to a new equilibrium. Meanwhile if we assume the skeptics are right, then we are never too far from the steady state because temperature is a random variable, and every positive shock to temperature will be eventually balanced out by a negative one. Recall that we assumed in our calibration that the current policy is a skeptic one. As can be seen from the steady state values, we are currently fairly close to the skeptic steady state. Capital and consumption are slightly below steady-state levels while emissions are slightly above. On the other hand the climate-aware steady state is very different. The intuition behind the numbers is as follows. The climate-aware policy-maker drastically reduces fossil-fuel consumption to avoid catastrophic climate change, moving the economy to a lower state. With less fossil fuel, marginal productivity of capital decreases, hence less capital is saved. With less capital and fossil fuel usage, less can be produced and hence consumed. This scaling back of the economy by a climate aware policy maker will be observed when we simulate the dynamic solution. 
Table 2: This table contains steady state and initial values for state and control variables for both climate-aware and climate-skeptic policies

\begin{tabular}{rrrr}
\hline & Real World & Skeptic & Aware \\
& & Stead State & Steady State \\
\hline Capital (\$ Trillion) & 200 & 215 & 174 \\
Consumption (\$ Trillion) & 245 & 261 & 225 \\
$\mathrm{CO}_{2}$ Emissions (ppmv) & 43 & 42.9 & 4.4 \\
$\mathrm{CO}_{2}$ Concentration (ppmv) & 388 & & 420 \\
Temperature (degrees C) & .75 & 0 & 1.65 \\
\hline
\end{tabular}

\section{Results}

\subsection{Skeptic Policymaker}

For the skeptic policy maker we used projection analysis to obtain a best approximation of the optimal consumption at each level of capital and global temperature. The resulting approximation is the following second-order polynomial function:

$\ln C_{t}=0.636+0.353 \ln K_{t}-.727 \ln \lambda\left(T_{t}\right)+0.0116\left(\ln K_{t}\right)^{2}-0.140 \ln K_{t} \ln \lambda\left(T_{t}\right)-2.06\left(\ln \lambda\left(T_{t}\right)\right)^{2}$

Hence consumption increases with current capital stock and decreases with survival probability. More capital results in more production and hence more consumption. On the other hand, when catastrophe probability increases, the effective discount factor decreases, leading the policymaker to consume more now and leave less capital for the future years.

To illustrate the solution above we plotted impulse response functions (IRF), showing how the economy reacts to a single standard deviation temperature shock in the first period, with the initial economy in the steady state. The IRF plots are presented in figures 2 - 1. As evident, the intuition gained from the optimal policy function is consistent with what we see in the impulse response function. With a positive shock to temperature, catastrophe probability increases. The policymaker fearing that a catastrophe will occur soon, discounts the future and increases consumption. The increase in consumption depletes capital. Capital remains low while the temperature is above the steady state, and so due to the scale effects consumption decreases as well. Over time as the temperature reverts to it's mean and the risk of catastrophe falls, capital and consumption increase until they are at the steady state value again.

What is less clear is what happens when the skeptic policymaker is wrong and climate change is real, but the optimal skeptic policy is implemented. To find out we used the same expression for optimal consumption in (4.1) but used the expression in (2.3) to simulate climate change as an endogenous process. We used the current real-world values 
of our state and choice variables from table 2 as starting values in our simulation. The resulting simulations are presented in figures $7-4$. The intuition behind the skeptic policy maker's response to endogenous climate change is as follows. The high level of fossil fuel consumption by the skeptic policymaker leads to climate change. Increased temperatures make the policymaker fear catastrophe (and a switch to a subsistence economy), leading to more consumption ${ }^{3}$. However, after a while this trend is reversed. Capital is diminished as a result of increased consumption. With a smaller capital stock, the marginal productivity of fossil fuels decreases reducing fossil fuel emissions and stabilizing temperature. It takes over 50 periods (500 years) but at the end the economy reaches a new steady state with slightly lower capital (\$174 Trillion) and consumption (\$243 Trillion) and higher temperatures (over 6 degrees above current levels). The surprising conclusion from these simulations is that even a completely skeptic policy does not result in runaway climate change. Though some climate change occurs, it eventually hits fairly high temperature values but stabilizes. Of course there is still significant welfare loss present, which will be discussed further in the Welfare Comparison section below.

\subsubsection{Sensitivity of Results to Assumptions}

A key assumption that arguably drives the result above is that capital is worthless after the catastrophe. This creates incentives for the skeptic to consume rather than invest in capital as catastrophe probability increases, hence scaling back capital and emissions. This assumption however is fairly extreme. It makes the catastrophe very close to an "end of the world" scenario, where no matter how much capital the humanity saves up before hand it is doomed for subsistence consumption. As mentioned earlier, we opted for the more extreme catastrophe scenario mainly due to its computational simplicity. In this section we try to argue that this extreme catastrophe is a decent approximation of less extreme catastrophic damage scenarios, and that this assumption does not drive our results. We do so, by comparing the dynamics under our doomsday scenario to a more realistic scenario of catastrophic climate change.

A less extreme scenario for a catastrophe would be a situation where the catastrophe drastically reduces the Total Factor Productivity(TFP), but with all the capital still available for use after the catastrophe. Assume that at the time of the catastrophe the capital stock is equal to some level $\bar{K}$, while the catastrophe lowers the TFP to $A=\bar{A}$. Immediately after the catastrophe, the representative agent begins eating through the capital. Because the catastrophe has dramatically lowered productivity, capital will not be replenished, and will start to diminish, until it reaches some subsistence steady state level. The higher the level of $\bar{K}$ - the more the representative agent can consume in the

\footnotetext{
${ }^{3}$ This phenomenon is consistent with results of Tsur and Zemel (2008) who showed that under a competitive solution, when consumers and firms do not observe the link between fossil fuels and climate change, more will be consumed resulting in more climate change
} 
few years immediately after the catastrophe. Thus before the catastrophe occurs, the representative agent has an incentive to save up more capital, so that he can consume more in the initial period after the catastrophe We can now see that with this less extreme scenario, as catastrophe probability increases there are two opposing incentives for the skeptical policymaker. On the one hand we have the mechanism that also existed in the doomsday scenario, where catastrophe results in more discounting and hence less saving. On the other hand we have the incentive to save up more, so more is available to consume after the catastrophe.

The important question is which of the two incentives dominate. If the incentive to save is insignificant relative to higher consumption due to increased discounting than even under a less extreme catastrophe, then our result of skeptics reducing emissions will hold. To determine whether it's true we examine the problem more rigorously (see Appendix A.3). What we take away from this analysis is as follows. As long as the decrease in productivity is relatively leage and demand relatively inelastic, the the marginal benefit of extra savings is fairly small. Thus we can argue that the effect of higher discounting which increases consumption and scales back the economy, will be much higher than the incentive to save up capital for the catastrophe. Therefore, the results that we obtained for the doomsday catastrophe scenario where the economy goes directly to subsistence consumption after the catastrophe, would still hold under a less extreme scenario of a significant decrease in productivity due to climate change. However for relatively milder catastrophes and more elastic demand functions this effect is reversed. Skeptics increase savings to prepare for catastrophic damages, ramping up production which in the end increases emissions even further. However, fully exploring these dynamics would take a whole separate paper so we leave this task for future research.

\subsection{Climate-Aware Policymaker}

The solution of the climate-aware policymaker's problem, obtained using a value function iteration algorithm is the best approximation of the value function. As the form of the approximation is fairly complex we don't present the expression here. Using the obtained approximation we perform Monte Carlo simulations of a climate-aware policymaker by finding the optimal consumption and fossil fuel at each point in time. The plots, representing average values of 100 Monte Carlo simulations are presented in figures 8 - 11 . The biggest difference between the skeptic and climate-aware policymakers is in the fossil fuel emissions. As can be seen in Figure 10 the climate-aware policymaker emits around 90 percent less than a skeptic one (around 4.6 ppmv compared to $42 \mathrm{ppmv}$ ). With fewer emissions the marginal productivity of capital decreases, so the climate-aware policymaker spends his savings, which decreases capital by $13 \%$ (Figure 9). With less capital available and less fossil fuels burned, less can be consumed, so consumption decreases as 
we (by around 10\% see (Figure 8). Eventually an equilibrium is reached where capital is $\$ 173$ Trillion, consumption is $\$ 222$ Trillion and emissions are 4.4 ppmv. Note that relative to the skeptic behavior in the face of man made climate change, long-run consumption and capital are about $10 \%$ lower while emissions are $90 \%$ lower. This is because reducing energy consumption (and hence emissions) affects production much less than a reduction in capital, due to lower marginal productivity of energy. As a result of the dramatic emission cuts very little climate change occurs less than 1.5 degrees, 3.5 degrees lower than the long-run skeptic temperature for a fully skeptic policymaker when facing man made climate change (Figure 11). The intuition behind the climate-aware policy maker's behavior is fairly straightforward - he reduces emissions to avoid the catastrophic climate change. Burning less fossil fuels reduces production, scaling back the economy and reducing capital and consumption.

We also simulate the optimal climate-aware policy function under the random climate change scenario (i.e. if the skeptics are right). We don't present the simulation plots here as they are fairly similar to the ones under man-made climate change. The climate-aware policymaker believes climate change is real, so he cuts fossil fuel emissions by scaling down production. In the random climate scenario the shocks can be persistent so temperature sometimes reaches much higher values. In these cases, the policymaker cuts emissions even lower, and increases consumption to match a decrease in fossil fuel with a decrease in capital. Once temperatures go back down, capital and emissions are restored back to the steady state.

\subsection{Mixed Expectations - Policymakers with Moderate Skepti- cism Levels}

The two cases presented in the previous sections are extremes - belief that climate change is man-made for sure, and a belief that human activity has no effect on our climate. In reality most people and policy-makers are somewhere in the middle - moderately skeptic. Thus it is worth examining the optimal policy of a policy maker who believes that climate change is man-made with a certain probability $\pi_{s} k \in(0,1)$. The problem of a moderately skeptic policy-maker is already outlined in Section 2, with the equation for evolution of climate expressed in (2.5). We derive the solution for policy makers with skeptic probability levels $\pi_{s} k=.1, .2 \ldots 9$. The solutions are then simulated for the same initial values, for both man-made climate change and random climate change scenarios.

We summarize the results of optimal behavior for moderate levels of skepticism with emission and temperature paths for each level of skepticism, simulated under the manmade climate change scenario (presented in Figures 12 and 13 respectively). As can be seen from the figures, the moderately-skeptic policy simulation results are much closer to the climate-aware policy simulation results. For skepticism levels below $60 \%$ annual 
emission levels are less than or equal to 5 ppm and final temperature change - between 1.5 and 2 degrees C. Furthermore, skepticism levels of 90 percent (corresponding to a 10 percent probability that climate change is connected to human activity) only results in emissions of $14 \mathrm{ppm}$ and a final increase in temperature of 3.5 degrees. The intuition behind this result lies in the catastrophic nature of damages. Given a potential in climate catastrophe, a policy maker will do everything possible to avoid temperature rise beyond a certain level. Thus once temperature reaches a certain level, even a very low probability that curtailing emissions will lead to a reduction in temperature is enough for stringent action.

\subsection{Welfare Comparison}

As can be seen from our policy simulations, the completely skeptic policy maker has a higher initial level of consumption (in both scenarios) but the climate-aware one has less climate change (in the man-made climate change scenario). Using the expression in (2.8) we compute expected discounted social welfare for both optimal policies under both scenarios. To do so we use Monte-Carlo analysis running one thousand simulations for each scenario and calculating the average discounted social welfare The results are presented below in Table 3 .

As can be seen from the results, for the exogenous climate change scenario the expected welfare of the skeptic is very close to that of the climate-aware policy maker. In the man-made climate change scenario however the welfare values are fairly different. The climate-aware policymaker dramatically cuts emissions and scales the economy back by reducing capital. However, in the long run that policy results in less climate change and preserves a high level of consumption in the initial periods. The climate-skeptic policy maker on the other hand does not reduce emission, leading to much higher climate change (5.5 degrees $\mathrm{C}$ ). This increase in temperature increases the discount rate, leading to a scale back in the economy (which also mitigates climate change). However, the resulting mitigation is too small (as emissions are still fairly high) while consumption and capital end up being lower than in the skeptic case, due to the higher discount rate. As a result under the man-made climate change scenario the welfare of the climate-skeptic is significantly lower.

The main question we are trying to answer is what is the cost of skepticism. To find out, we compare the welfare loss of the two possible 'mistakes': picking the skeptic policy if the climate scientists are right versus picking the climate-aware one if the skeptics are right. The welfare loss of mistaken skepticism is 2.91 times as large as that of a mistaken belief in climate change. The conclusion we draw from this result is the following: given a choice between a completely skeptic policy or a completely environmentally stringent policy, any policy maker who believes there is more than 25 percent chance that climate 
change is real should prefer the latter.

Table 3: This table contains social welfare computations for both climate-aware and climate-skeptic policies under random and man made climate change scenarios

\begin{tabular}{rrr}
\hline & Random Climate Change & Man-made Climate Change \\
\hline Skeptic Policy & -4.52 & -7.81 \\
Climate-Aware Policy & -5.30 & -5.54 \\
\hline
\end{tabular}

To further determine how skepticism affects welfare, we examine welfare values for the levels of belief in man-made climate change, using our mixed expectation solutions presented in Section 4.3. We compute welfare for the policy simulation for each level of skepticism for both the man-made and random climate change scenario. The plots of welfare values are presented in Figure 14. The results indicate that welfare is fairly similar under a random climate change scenario regardless of skepticism (as resulting policies are similar). Furthermore welfare is flat under a man-made climate change scenario for skepticism below 60 percent, under decreases fairly slowly after that. This result reinforces a conclusion made earlier, that even for fairly high levels of climate skepticism, a stringent environmental policy is still preferable.

\section{Conclusion}

Despite overwhelming scientific evidence of man-made climate change, many policymakers are still skeptical about it. We study climate skepticism in a formal theoretical framework to determine how a skeptic policymaker responds to a potential climate catastrophe. The climate catastrophe in question is an abrupt catastrophic event, which occurs at an uncertain time, and reduces all global consumption to a subsistence level. The probability of a catastrophic event increases with global temperature. Temperature is perceived as random by a fully skeptic policymaker and emission-driven by a climate aware one, while moderate skeptics assign probability values to each possibility.

We find that catastrophic climate change increases the effective discount rate in the climate skeptic case. Thus when the probability of catastrophe increases, the completely skeptic policymaker increases consumption, diminishing savings. These diminishing savings will in the long-run limit the consumption of the skeptic, decreasing fossil-fuel emissions and slowing down climate change. Thus, in face of a catastrophe, a completely skeptic policy does not lead to unlimited climate change.

On the other hand a climate-aware policy maker will scale back the economy right away, decreasing emissions and avoiding climate change almost entirely. The welfare loss of that scale-back is relatively small compared to the climate change resulting from a fully skeptic policy. Furthermore, the cost of unnecessary emission cuts incurred by the 
climate aware if the completely skeptic are right is much smaller than the climate change damages incurred by the completely skeptic if the climate-aware are right. Additionally, we find that due to catastrophic consequences of climate change, even policy-makers with low levels of belief in man-made climate change will implement a stringent environmental policy.

The overarching conclusion of this study is that potential catastrophic climate change damages lead to emission reduction regardless of the level of skepticism. Thus a potential application of this theoretical exercise would be that more effort should be focused on educating the public on potential catastrophic damages of climate change. As long as the public is convinced that climate change leads to catastrophe they will support a stringent environmental policy regardless how skeptical they are of man-made climate change.

We have made some restrictive assumptions in order to make the problem tractable. One of these assumptions, as has been mentioned before, is the fact that all capital is destroyed at the time of catastrophe. We have done some calculations in section 4.1.1 to argue that the main result will still hold without this assumption. This case would be strengthened with a formal rigorous analysis of the skeptic problem with endogenous post-catastrophe capital. Another restrictive assumption is holding $\pi_{s k}$ the skepticism parameter constant over time. Hence allowing learning on the $\pi_{s k}$ parameter, so that the agent can change the level of skepticism with new evidence about temperature would be an interesting problem to explore. Lastly, studying the problem of multiple agents with various level of skepticism as opposed to a representative agent problem would be a more realistic model of the world.

\section{References}

Stergios Athanassoglou and Anastasios Xepapadeas. Pollution control with uncertain stock dynamics: When, and how, to be precautious. Journal of Environmental Economics and Management, 63(3):304 - 320, May 2012.

Benjamin Crost and Christian P. Traeger. Risk and aversion in the integrated assessment of climate change. Department of Agricultural and Resource Economics, UC Berkeley, Working Paper Series qt1562s275, Department of Agricultural and Resource Economics, UC Berkeley, 2011.

Magnus Hennlock. Robust control in global warming management: An analytical dynamic integrated assessment. Working papers in economics, Gteborg University, Department of Economics, April 2009.

Larry Karp and Yacov Tsur. Time perspective and climate change policy. Journal of Environmental Economics and Management, 62(1):1-14, July 2011. 
Klaus Keller, Benjamin M Bolker, and David F Bradford. Uncertain climate thresholds and optimal economic growth. Journal of Environmental Economics and Management, 48(1):723 - 741, 2004.

David L. Kelly and Charles D. Kolstad. Bayesian learning, growth, and pollution. Journal of Economic Dynamics and Control, 23(4):491-518, February 1999.

Andrew J. Leach. The climate change learning curve. Journal of Economic Dynamics and Control, 31:1728-1752, 2007.

Anthony Leiserowitz, Edward Maibach, Connie Roser-Renouf, Geoff Feinberg, and Peter Howe. Extreme weather and climate change in the american mind: April 2013. Yale project on climate change communication, Yale University and George Mason University, 2013.

Derek M. Lemoine and Christian P. Traeger. Tipping points and ambiguity in the economics of climate change. Working Paper 18230, National Bureau of Economic Research, July 2012.

NOAA. Annual mean growth rate for mauna loa, hawaii. Trends in atmospheric carbon dioxide, NOAA Earth Systems Laboratory, 2010.

William D. Nordhaus. An optimal transition path for controlling greenhouse gases. Science, 258:1315-1319, June 1992.

William D. Nordhaus. A Question of Balance: Weighing the Options on Global Warming Policies. Yale University Press, 2008.

William D. Nordhaus and David Popp. What is the value of scientific knowledge? an application to global warming using the price model. The Energy Journal, 18:1-47, March 1997.

Robert S. Pindyck. Uncertain outcomes and climate change policy. Journal of Environmental Economics and Management, 63(3):289-303, 2012.

William A. Pizer. The optimal choice of climate change policy in the presence of uncertainty. Resource and Energy Economics, 21(3-4):255-287, August 1999.

Armon Rezai, Frederick van der Ploeg, and Cees Withagen. The optimal carbon tax and economic growth: Additive versus multiplicative damages. OxCarre Working Paper 94, Oxcarre University of Oxford, 2012.

Nicholas Stern. The Economics of Climate Change: The Stern Review. Cambridge University Press, Campridge, 2007. 
Yacov Tsur and Cees Withagen. Preparing for catastrophic climate change. Journal of Economics, pages 1-15, 2012. ISSN 0931-8658.

Yacov Tsur and Amos Zemel. Regulating environmental threats. Environmental \& Resource Economics, 39(3):297-310, March 2008.

Yacov Tsur and Amos Zemel. On the dynamics of competing energy sources. Automatica, 47, October 2009.

Sweder Van Wijnbergen and Sweder Willems. Optimal learning on climate change: Why climate skeptics should reduce emissions. Tinbergen Institute Discussion Papers 12085/2, Tinbergen Institute, August 2012.

Martin L. Weitzman. On modeling and interpreting the economics of catastrophic climate change. The Review of Economics and Statistics, 91(1):1-19, 2009. 


\section{A Appendix}

\section{A.1 Projection Method Used to Solve the Skeptic Problem}

The main idea behind projection analysis is to identify a function $P\left(K_{t}, T_{t}\right)$, which approximates the optimal consumption $\hat{C}_{t}$. We begin by identifying a grid $\left[K_{M I N}, K_{M A X}\right] \times$ $\left[T_{M I N}, T_{M A X}\right]$ on which we want to approximate the optimal solution. In the skeptic expectations case, temperature only appears in the agent's utility functions as $\lambda\left(T_{t}\right)$ hence it is reasonable to construct a grid on $\lambda\left(T_{t}\right)$ rather than $T_{t}$ itself. We then pick a functional form for the approximation $P\left(K_{t}, \lambda_{t}\right)$. In this case we use a fairly simple we use a n-th order polynomial (but more complex functions may be used as well). Then for every grid point $K_{l}, \lambda\left(T_{m}\right) \in\left[K_{M I N}, K_{M A X}\right] \times\left[\lambda\left(T_{M I N}\right), \lambda\left(T_{M A X}\right)\right]$, the approximate optimal consumption level is specified by:

$$
\ln P\left(K_{l}, \lambda\left(T_{m}\right)\right)=\sum_{i=0}^{n} \sum_{j=0}^{n-i} g_{i j}\left(\ln K_{l}\right)^{i} \ln \left(\lambda\left(T_{m}\right)\right)^{j}
$$

All that remains is to identify the coefficients $g_{i j}$ that give the closest approximation of optimal consumption. Let $g=\left\{g_{i j}\right\}_{i, j=1, \ldots, n}$ be a set of coefficients identifying an approximation of optimal consumption $P^{g}$. Then, for each such coefficient set $g$ we can compute $\operatorname{Error}(g)$ (a measure of how good our approximation is), by summing the difference between the left hand side and the right hand side of the Euler equation (defined in (3.6)) for each grid point.

The only complicating factor in computing $\operatorname{Error}(g)$ is the expectations operator. However, because the stochastic component of the climate process is normally distributed, we can use Gaussian-Quadrature to numerically approximate expectation. Then we apply a Newton-Rhapson algorithm to find the coefficients $g$ that minimize $\operatorname{Error}(g)$, and hence give us the best approximation.

\section{A.2 Value Function Iteration Method Used to Solve the Skeptic Problem}

Our goal is to find a function $V$ such that it is the fixed point of the following problem:

$$
V\left(K_{t}, S_{t}, T_{t}\right)=\max _{C_{t}, X_{t}} U\left(C_{t}\right)+\left(1-\lambda\left(T_{t}\right)\right) \psi+\rho \lambda\left(T_{t}\right) E\left(V\left(K_{t+1}, S_{t+1}, T_{t+1}\right)\right)
$$

Approximating $V$ around a steady state value would defeat the point as is often when solving IAMs the steady state is 100 years into the future, thus we need to know the optimal behavior far from the steady state. Purely grid-based methods (finding the optimal value for $V$ at every point) would be too burdensome - with 3 state variables and 
2 control variables plus 1 stochastic component, a fine grid would require too many grid points. Thus we turn towards a flexible function approximation of $V$. We still of course need a grid over which to fit the value function, but this grid can be a lot sparser with a flexible function form.

Let $\Phi\left(K_{t}, S_{t}, T_{t} ; \chi\right)$ be a family of functions, parameterized by vector $\chi$. Then the closest approximation to $V$ corresponds to some $\chi$. There are many potential functional forms for $\Phi$. We use following neural network approximation (same as the one used in Kelly and Kolstad (1999)):

$$
\Phi\left(K_{t}, S_{t}, T_{t} ; \chi\right)=\sum_{l=0}^{L} \chi_{1 l} \tanh \left(\chi_{2 l} K_{t}+\chi_{3 l} S_{t}+\chi_{4 l} \lambda\left(T_{t}\right)+\chi_{5 l}\right)+\chi_{6}
$$

We use the following algorithm to find the set of parameters $\chi$ such that $\Phi\left(K_{t}, S_{t}, T_{t} ; \chi\right)$ is the best approximation of $V$ :

1. Create a grid. Pick a starting value for the value function $V_{j 0}$ at every grid point $j$.

2. Using a numerical solver find $\chi_{0}$ such that it minimizes

$$
\sum_{j}\left(\Phi\left(K_{j} S_{j} T_{j} ; \chi_{0}\right)-V_{j 0}\right)^{2}
$$

3. At every grid point $j$ find the optimal control $C_{j}$ and $X_{j}$ by maximizing

$$
V_{j, 1}=\max _{C_{t}, X_{t}} U\left(C_{t}\right)+\left(1-\lambda\left(T_{t}\right) \psi+\rho \lambda\left(T_{t}\right) E\left(\Phi\left(K_{t+1}, S_{t+1}, T_{t+1} ; \chi_{0}\right)\right)\right.
$$

4. Find $\chi_{1}$ by using a numerical solver to minimize

$$
\sum_{j}\left(\Phi\left(K_{j} S_{j} T_{j} ; \chi_{1}\right)-V_{j, 1}\right)^{2}
$$

5. Repeat steps 2-4, until $\max _{j}\left|V_{j, i}-V_{j, i-1}\right|<\zeta$ (where $\zeta$ is some fixed convergence threshold).

The value function is approximated on a grid around the steady state, using a small grid of 10 points for each state variable $(N=1000$ points total). To provide sufficient flexibility for the function it is suggested that the size of the parameter vector $\chi(5 \mathrm{~L}+1)$ should be around $\sqrt{(} N)$ (where $N$ is the total number of grid points). We set $L=6$ for a total of 31 parameters. 


\section{A.3 Endogeneity of Capital Post Catastrophe: Formal Deriva- tion}

Most of the analysis in our study concerns the case where the pre-catastrophe level of capital is not relevant after the catastrophe. In this section we investigate the problem, where the catastrophe is of a more complex nature: total factor of productivity is lowered but all capital accumulated before the catastrophe is available for production/consumption use. We limit our attention to the skeptic policymaker case as that is the case most affected by this assumption. The analysis in this section serves as a robustness check against the assumptions we make about the catastrophe in the rest of the paper.

Assume that after the catastrophe occurs the total factor productivity becomes $A=\bar{A}$. Let $\bar{t}$ be the catastrophe time and $\bar{K}$ be the level of capital at the time of catastrophe. For every level of $\bar{K}$ there is $\hat{K}_{\bar{t}}(\bar{K}), \hat{K}_{\bar{t}+1}(\bar{K}) \ldots$ and $\hat{K}_{\bar{t}}(\bar{K}), \hat{K}_{\bar{t}+1}(\bar{K}) \ldots$ which represent the utility-maximizing post-catastrophe capital and consumption. Then the expression of the skeptic social welfare becomes

$$
\sum_{t=0}^{\infty} \rho^{t}\left(U\left(C_{t}\right)+\psi\left(K_{t}\right)\left(1-\lambda\left(T_{t}\right)\right)\right) Y(t)
$$

where

$$
\begin{gathered}
Y(t)=\left\{\begin{array}{cc}
1 & t=0 \\
\prod_{j=0}^{t-1} \lambda\left(T_{j}\right) & t>0
\end{array}\right. \\
\psi\left(K_{t}\right)=\sum_{i=t}^{\infty} \hat{C}_{i}\left(K_{t}\right)
\end{gathered}
$$

. Then the resulting F.O.C. are:

$$
\begin{array}{r}
U^{\prime}\left(C_{t}\right)-\left(1-\lambda\left(T_{t}\right)\right) \psi^{\prime}\left(K_{t}\right)=E\left(U^{\prime}\left(C_{t+1}\right) \rho \lambda\left(T_{t}\right)\left((1-\delta)+F_{K}\left(K_{t+1}, X_{t+1}\right)\right)\right) \\
F_{X}\left(K_{t}, X_{t}\right)=p
\end{array}
$$

Recall that one of the key results in the paper was driven by the fact that as temperature increases, the skeptic consumes more due to increased discounting. This leads the skeptic to eat through the capital which in turn scales back the economy. Using the F.O.Cs we can examine whether that happens now. From the expression above we can derive that:

$$
\frac{d U^{\prime}\left(C_{t+1}\right)}{d \lambda\left(T_{t}\right)}=\frac{-\lambda\left(T_{t}\right)^{-2}\left(U^{\prime}\left(C_{t}\right)-\psi^{\prime}\left(K_{t}\right)\right.}{\rho\left((1-\delta)+F_{K}\left(K_{t+1}, X_{t+1}\right)\right.}
$$

As the utility function is increasing in $C$ while $\lambda$, the survival probability function is decreasing in $T$ we can use this expression to determine, how next period consumption (conditional on current consumption and capital) reacts to an increase in capital. The sign of the expression on the right hand side is ambiguous. Note that if $\psi^{\prime}\left(K_{t}\right)=0$ 
as we have assumed in the rest of the paper, the expression on the right hand side is clearly negative, meaning as survival probability decreases, consumption is increased. This is the effect of discounting we have described. However, with the introduction of endogenous capital the effect becomes ambiguous. However, as long as $U^{\prime}\left(C_{t}\right)>\psi^{\prime}\left(K_{t}\right)$, the skeptic will still increase consumption as the catastrophe probability increases. The interpretation of this fact is as follows. At each point in time the skeptic compares the marginal benefit of consuming now versus saving up capital for the rainy day when the catastrophe occurs. As long as consumption is more preferable, then the discounting effect still holds, and our results would be valid even with this catastrophe scheme.

The F.O.C's expressed (A.8) - (A.9) are fairly complex so we do not fully solve the model here. However we can use the F.O.C's to numerically solve for the steady state. We set $\bar{A}=.75 A=2.13$, meaning that the catastrophe leads to a $25 \%$ drop in TFP. We further lower the coefficient of relative risk aversion to 1.1 making demand less elastic. This leads to the post-catastrophe steady state capital of approximately 66 trillion, and post-catastrophe steady state consumption of 110 trillion. We use a shooting algorithm to find the optimal saddle path of capital and consumption and then estimate a polynomial approximation of marginal post-catastrophe welfare increase $\psi^{\prime}(K)$. Then we find the new pre-catastrophe steady state capital and consumption. Using these values we test the expression in (A.10) and find that the right hand side of that expression is negative. Therefore we can conclude that the "discouting incentive" dominates the "precautionary incentive": if at the steady state, there is an increase to temperature, the skeptic policymaker would increase consumption fearing the catastrophe. Note however, that this occurs for relatively large catastrophes and relatively inelastic demand specification. 


\section{A.4 Simulation Plots}

\section{A.4.1 Skeptic Optimal Policy Simulated for the Skeptic Scenario}

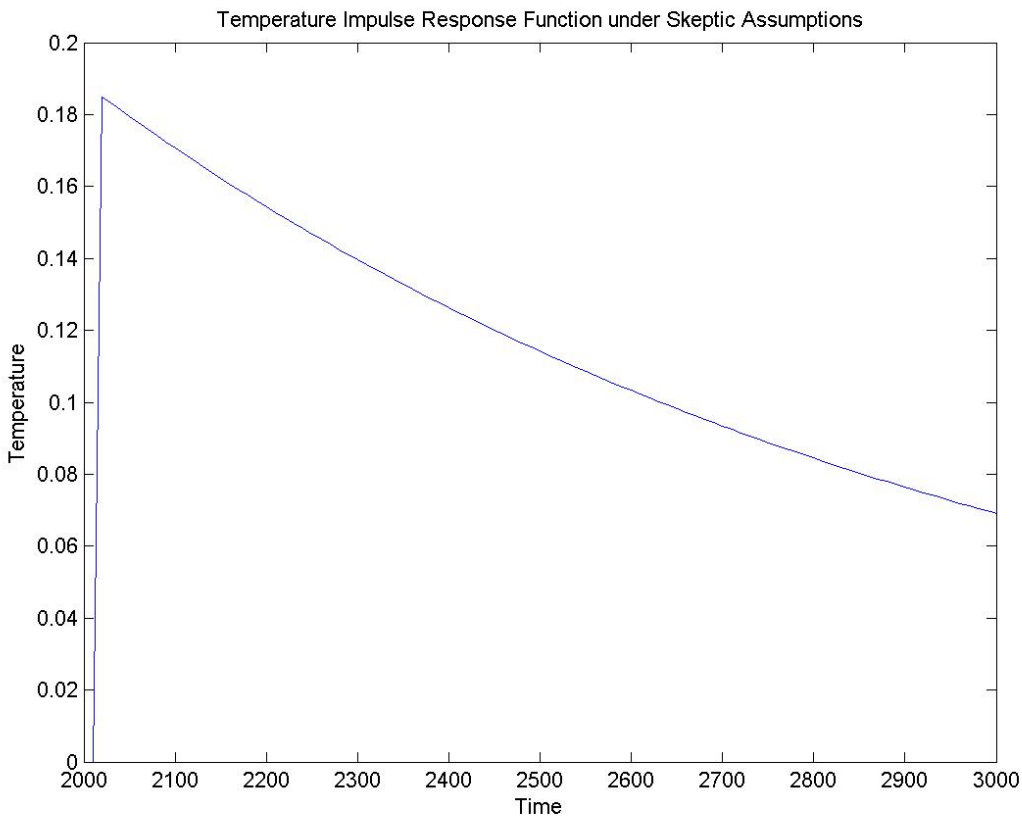

Figure 1: Impulse response plot: Simulation of the behavior of the temperature according to skeptics, after a single standard deviation shock 


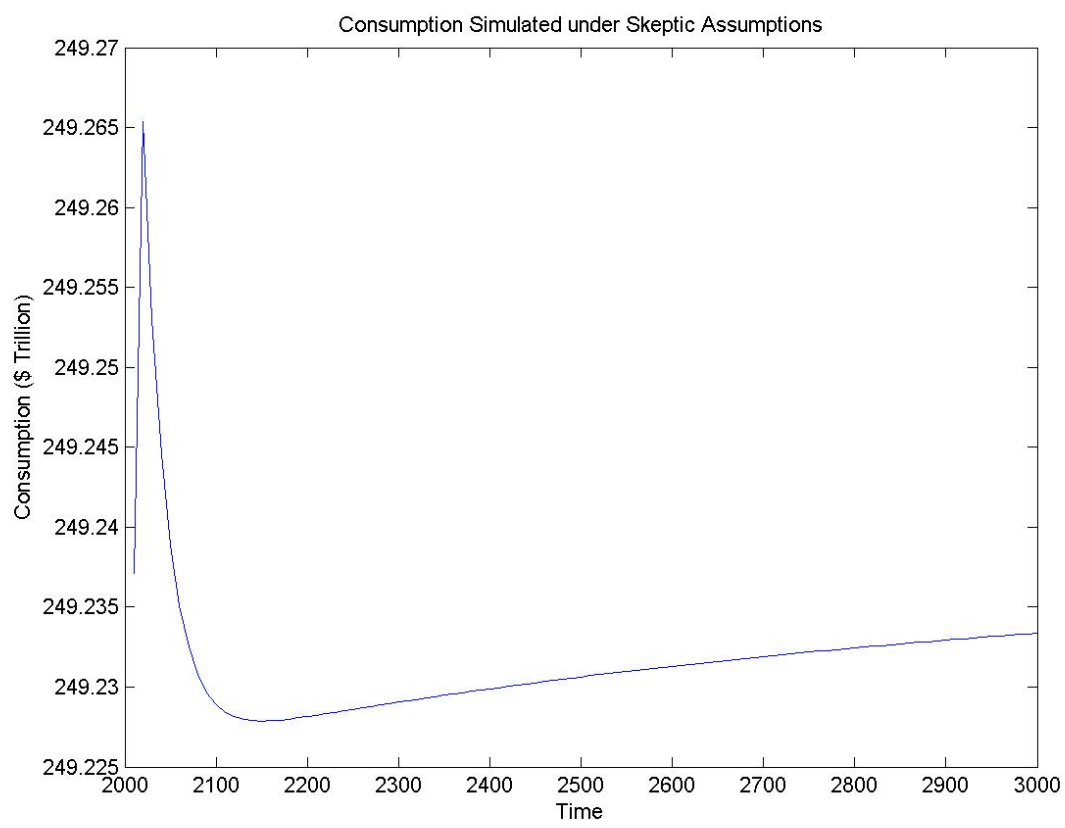

Figure 2: Impulse response plot: Simulation of the optimal consumption path of the skeptic after a single standard deviation shock to temperature

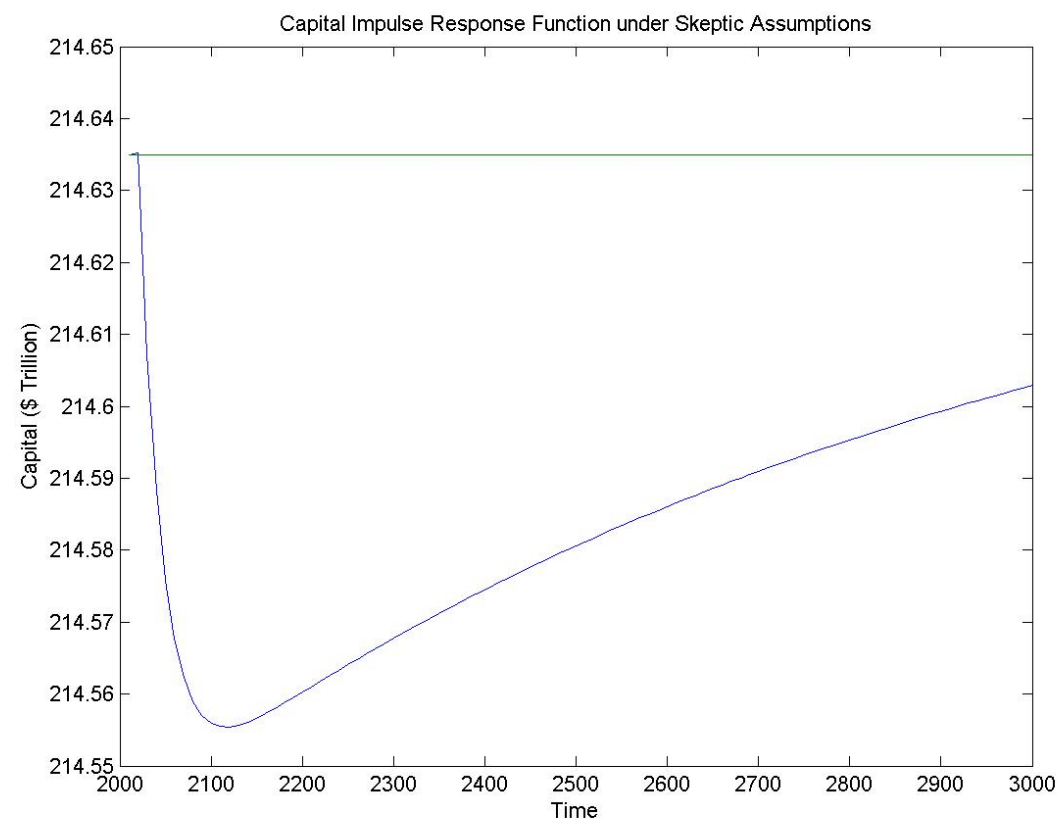

Figure 3: Impulse response plot: Simulation of the optimal capital path of the skeptic after a single standard deviation shock to temperature 


\section{A.4.2 Skeptic Optimal Policy Simulated for Manmade Climate Change Sce- nario}

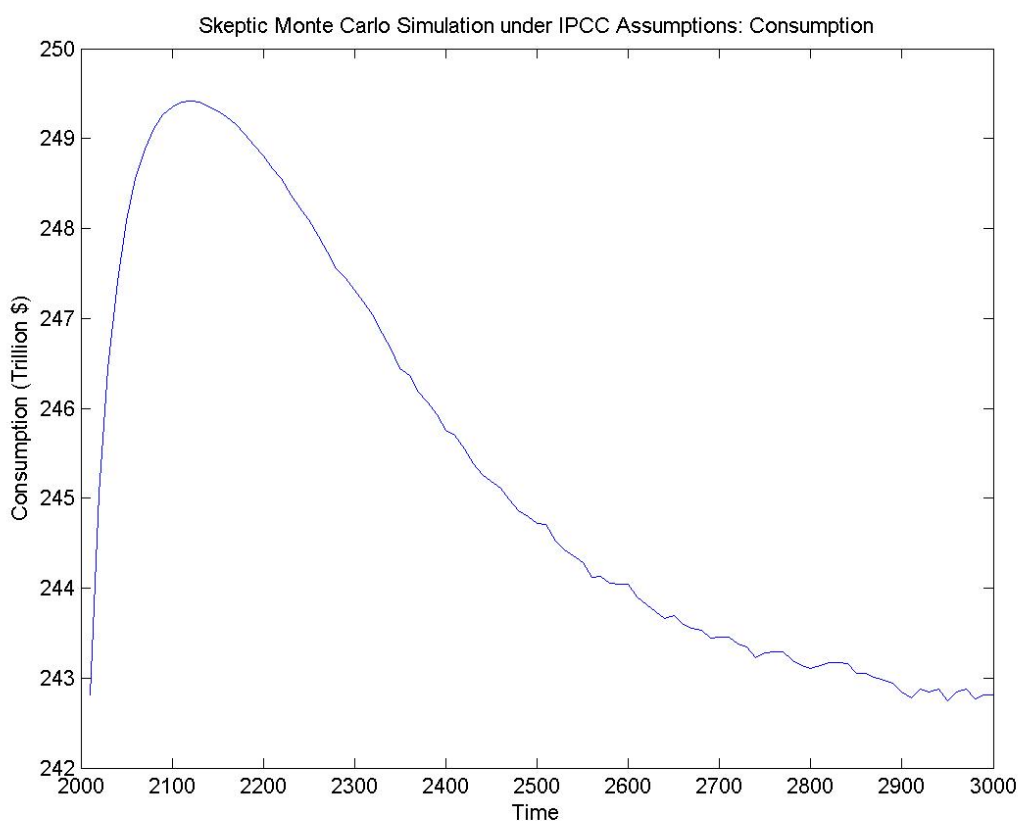

Figure 4: Montecarlo simulations of optimal skeptic policy simulated for man-made climate change scenario for 1000 years - Consumption path. Plot represents an average of 1000 runs. 


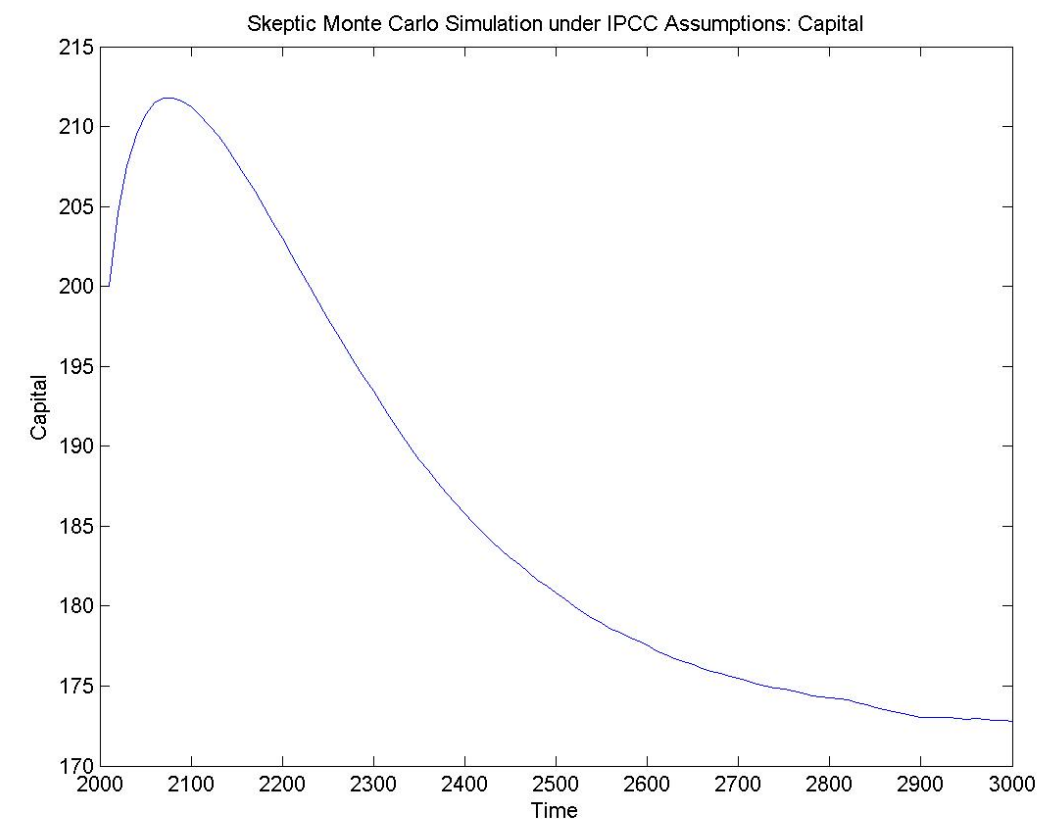

Figure 5: Montecarlo simulations of optimal skeptic policy simulated for man-made climate change scenario for 1000 years - Capital path. Plot represents an average of 1000 runs.

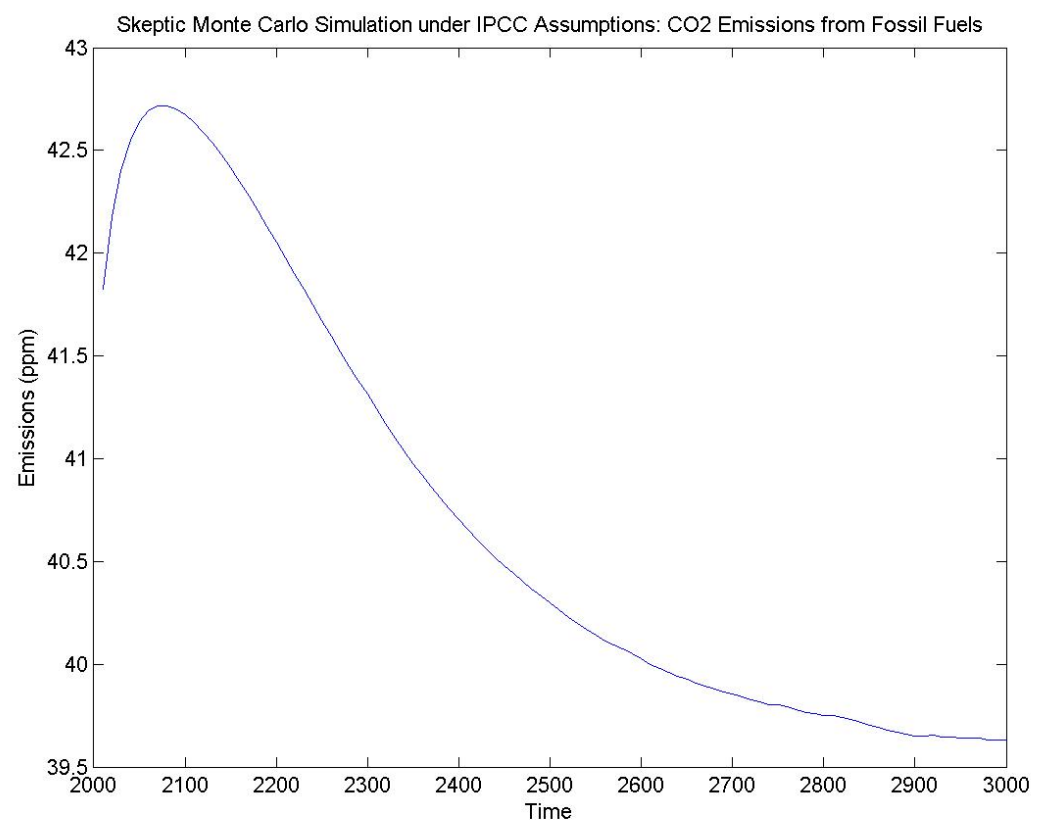

Figure 6: Montecarlo simulations of optimal skeptic policy simulated for man-made climate change scenario for 1000 years - $\mathrm{CO}_{2}$ emissions path. Plot represents an average of 1000 runs. 


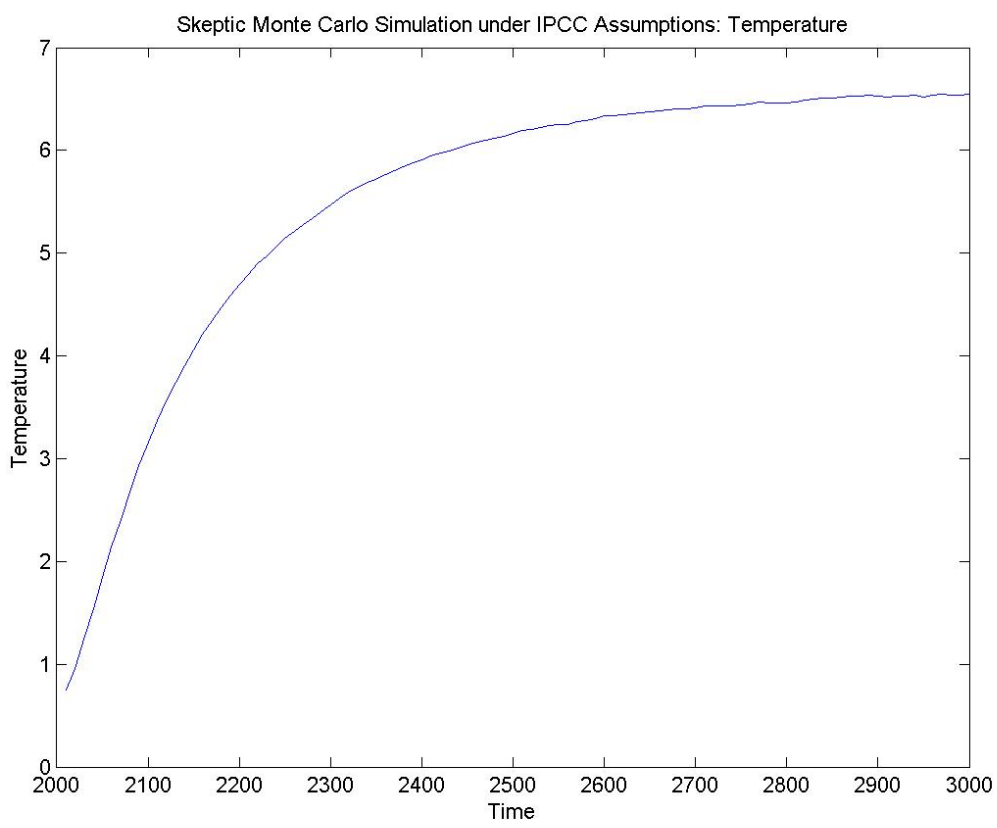

Figure 7: Monte Carlo simulations of optimal skeptic policy simulated for man-made climate change scenario for 1000 years - Temperature path. Plot represents an average of 100 runs. 


\section{A.4.3 Climate Aware Optimal Policy Simulated for the Manmade Climate Change Scenario}

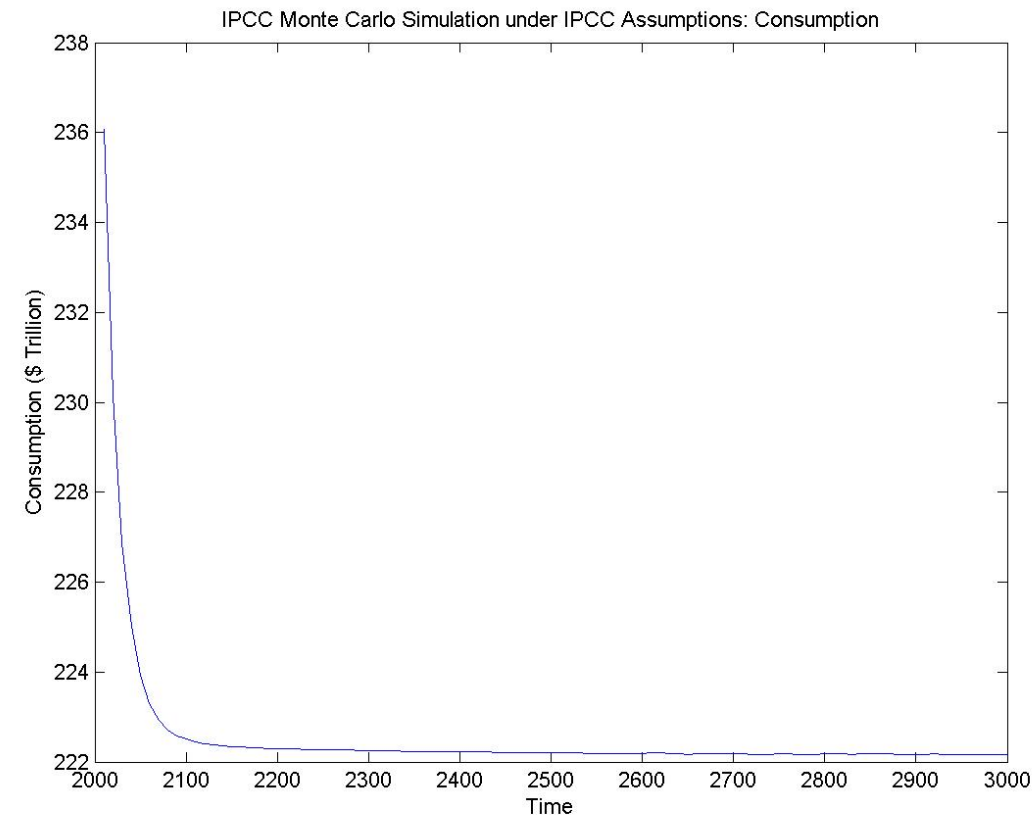

Figure 8: Monte Carlo simulations of optimal climate-aware policy simulated for manmade climate change scenario for 1000 years - Consumption path. Plot represents an average of 100 runs. 


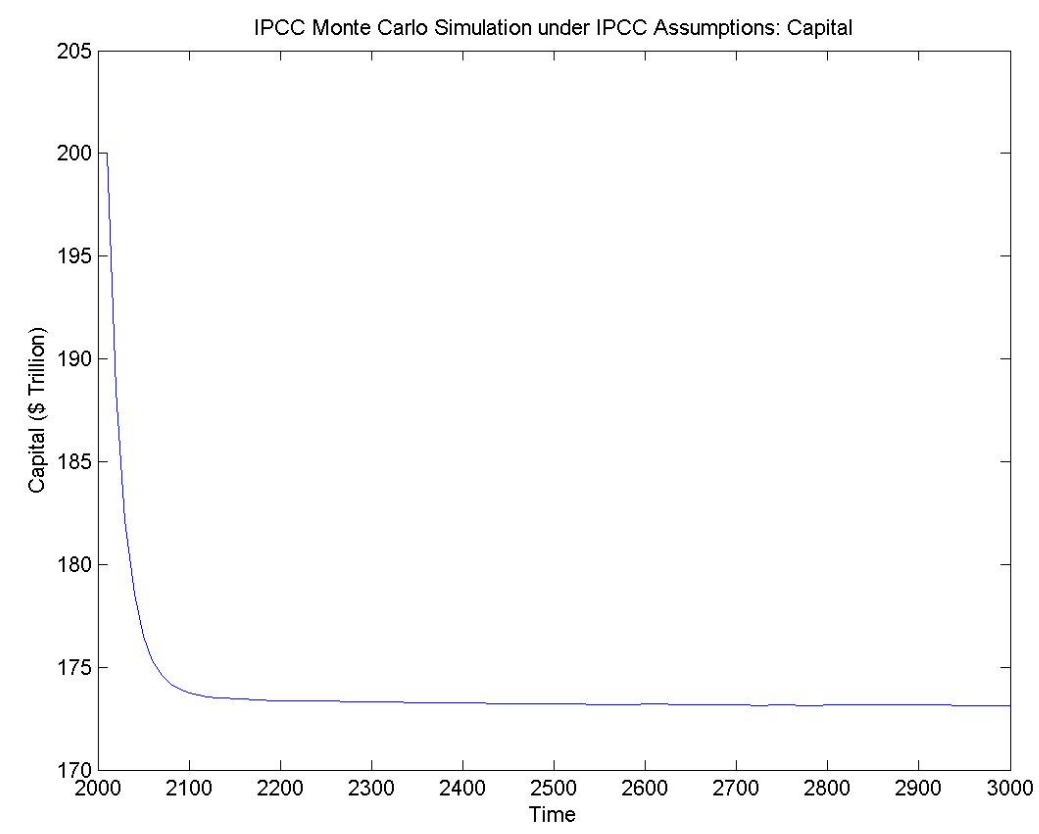

Figure 9: Monte Carlo simulations of optimal climate-aware policy simulated for manmade climate change scenario for 1000 years - Capital path. Plot represents an average of 100 runs.

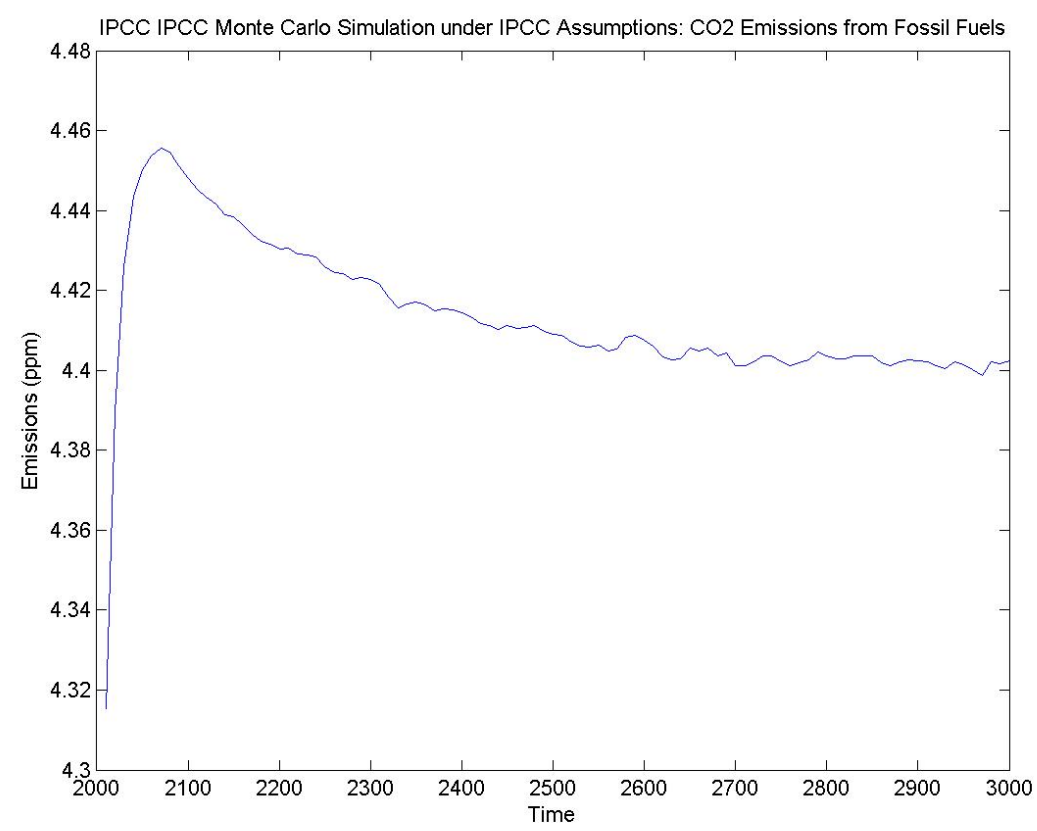

Figure 10: Monte Carlo simulations of optimal climate-aware policy simulated for manmade climate change scenario for 1000 years - $\mathrm{CO}_{2}$ emission path. Plot represents an average of 100 runs. 


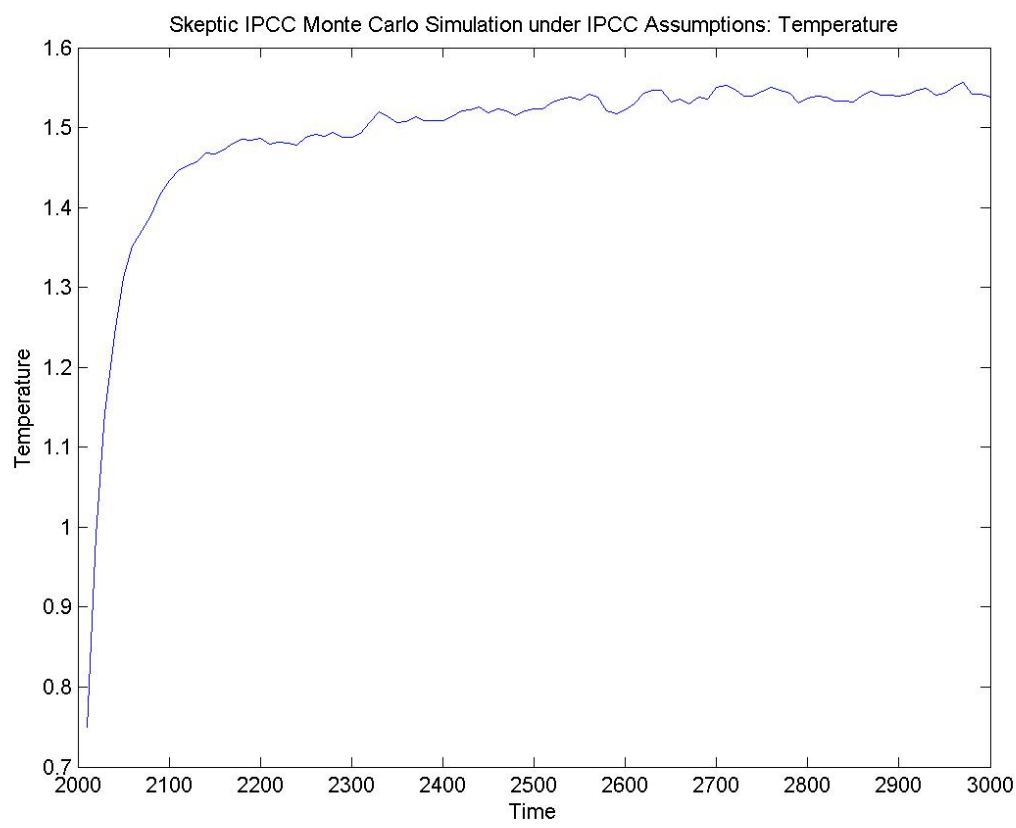

Figure 11: Monte Carlo simulations of optimal climate-aware policy simulated for manmade climate change scenario for 1000 years - Temperature path. Plot represents an average of 100 runs. 


\section{A.4.4 Optimal Policy for Mixed Expectations Simulated under man-made Climate Change Assumptions}

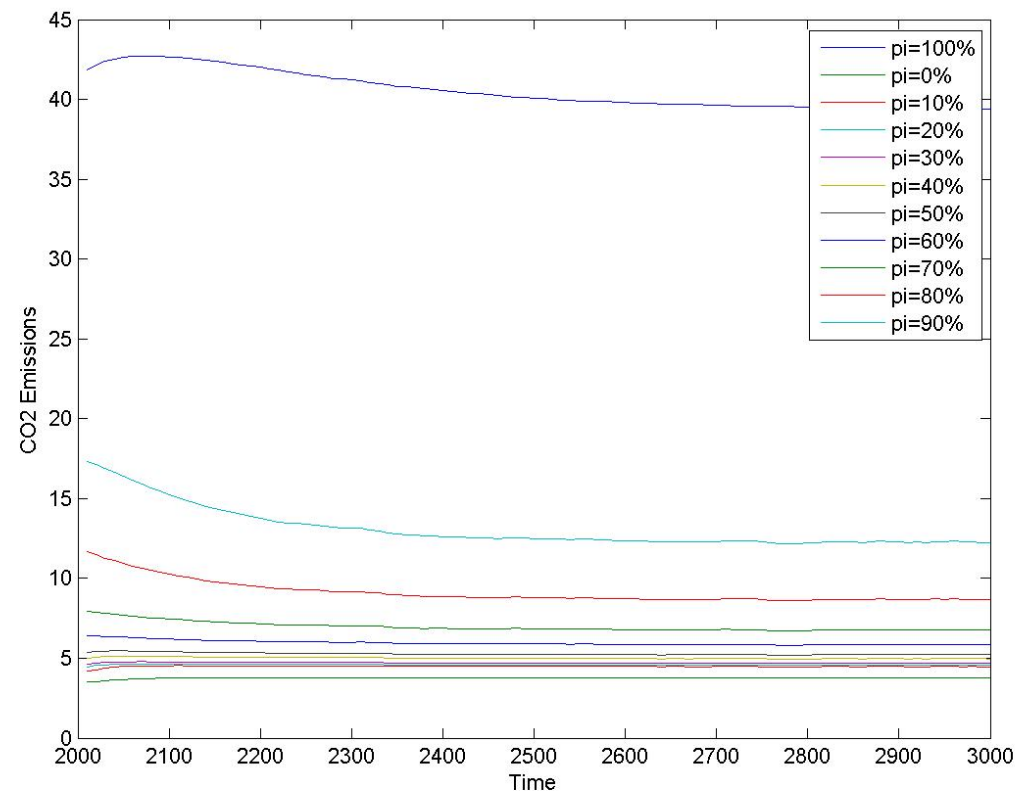

Figure 12: Optimal policy under various levels of skepticism (skeptic probability $\pi$ between 0 and 1 at intervals of .1) simulated for man-made climate change scenario for 1000 years - CO2 Emission path. Path represents an average of 100 simulation runs. 


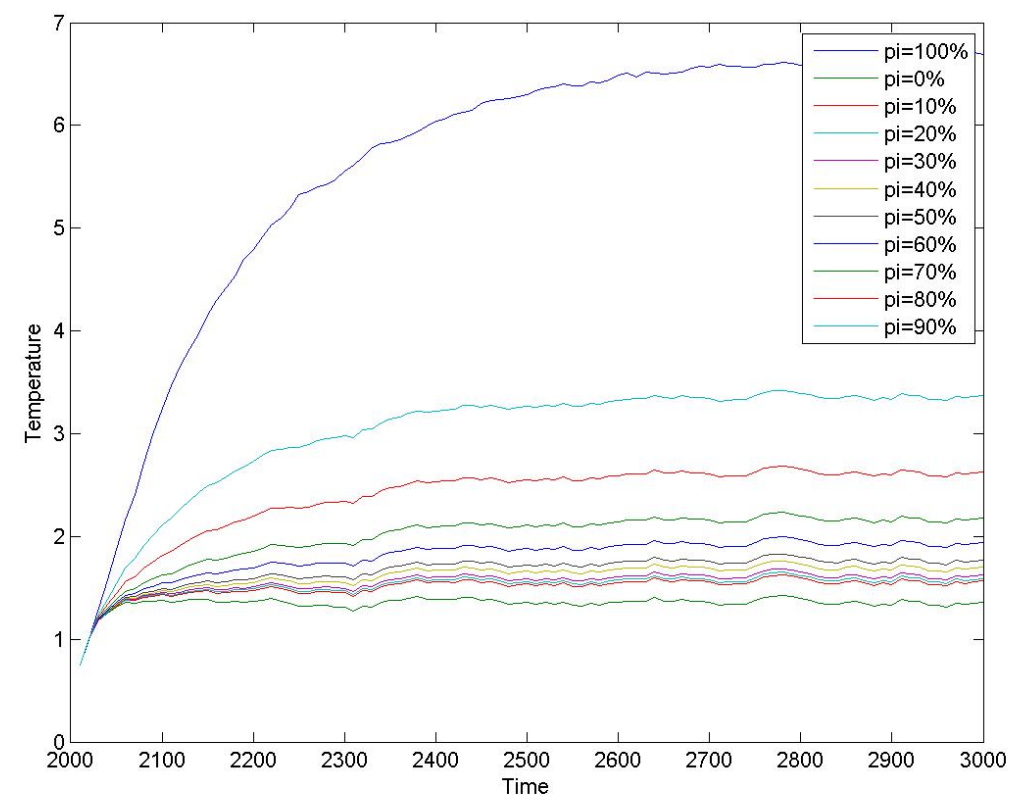

Figure 13: Optimal policy under various levels of skepticism (skeptic probability $\pi$ between 0 and 1 at intervals of .1)simulated for the man-made climate change scenario for 1000 years - Temperature path. Path represents an average of 100 simulation runs.

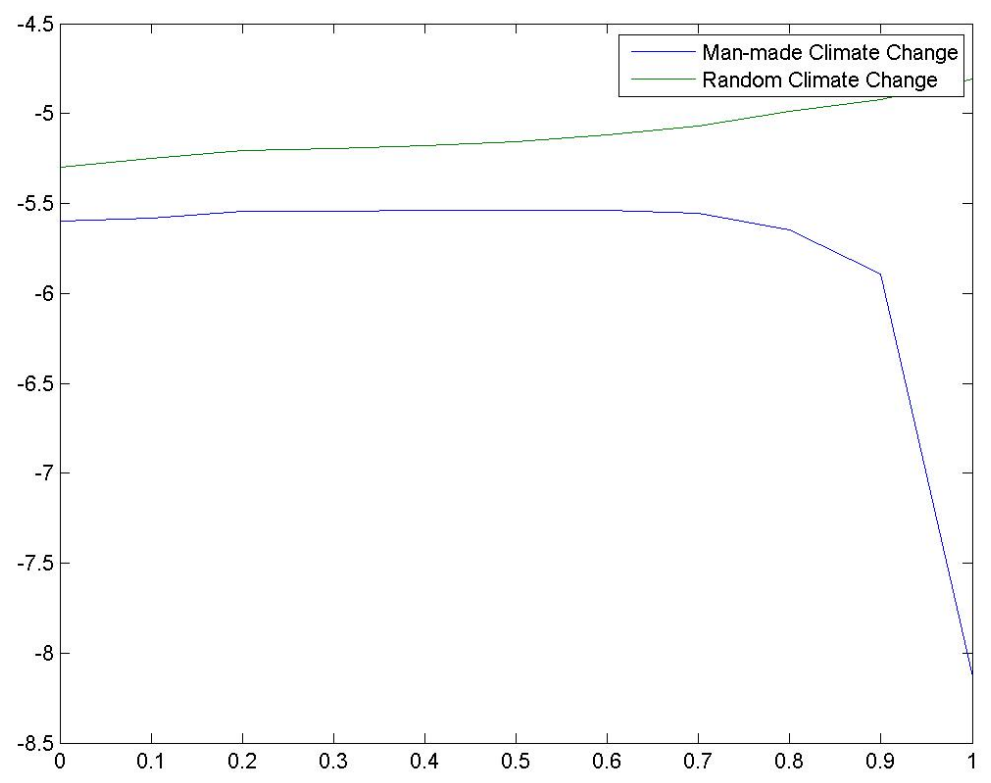

Figure 14: Welfare levels, computed by simulating the optimal policy for various levels of skepticism simulated for the man-made and random climate change scenarios. Welfare averaged over 100 simulation runs. 